\title{
Effect of the peripubertal pattern of LH and FSH secretion on in-vitro oestradiol-17ß secretion and follicular growth within juvenile rat ovaries
}

\author{
J. J. Peluso \\ Department of Obstetrics and Gynecology, University of Connecticut Health Center, Farmington, \\ CT 06032, U.S.A.
}

\begin{abstract}
Summary. Juvenile rat ovaries were placed in perifusion culture and exposed to (1) no gonadotrophin, (2) tonic NIH-FSH (200 ng RP-1 equiv./ml) or (3) NIH-FSH + NIHLH pulses $(2 / \mathrm{h}$, amplitude $=80 \mathrm{ng} \mathrm{RP}-1$ equiv. $/ \mathrm{ml})$. After $3 \mathrm{~h}$ of perifusion, the ovaries were prepared for histological analysis and the perifusate assayed for oestradiol-17 $\beta$. Since the NIH-FSH preparation is contaminated with $\mathrm{LH}$, a second experiment was conducted using recombinant bovine LH and FSH. Ovaries were perifused for $3 \mathrm{~h}$ with (1) no hormones, (2) recombinant FSH (200 $\mathrm{ng} / \mathrm{ml}$ ) or (3) recombinant FSH plus $25 \mathrm{ng}$ recombinant $\mathrm{LH} / \mathrm{ml}$. NIH-FSH alone increased the number of mid-size antral follicles $(P<0.05)$ and decreased the number of small antral follicles $(P<0.05)$. Pulsatile LH in the presence of FSH increased the number of mid-size antral follicles without reducing the number of small antral follicles. Studies with recombinant FSH and LH demonstrated that both FSH and LH are necessary to stimulate follicles to grow, indicating that the growth-promoting property of the NIH-FSH is due to the presence of both FSH and LH. Regardless of whether NIH or recombinant gonadotrophins were used, follicular growth was induced without increasing oestradiol secretion. These results demonstrate that enhanced oestradiol secretion is not essential for the induction of follicular growth, while both LH and FSH are necessary to stimulate small antral follicles to grow into mid-size antral follicles. Since the peripubertal pattern of $\mathrm{LH}$ and FSH secretion stimulates in-vitro follicular development within the juvenile ovary, this pattern of gonadotrophin presumably represents at least part of the stimulus that facilitates the transition into the peripubertal stage.
\end{abstract}

Keywords: puberty; LH; FSH; follicular growth; oestradiol-17ß; rat

\section{Introduction}

On each day of life, a group of primary follicles leave the non-proliferating pool of follicles and start to grow. In mice, the number of follicles that start to grow is greatest during the first 2 weeks of life then decreases to an average of between 17 and 20 new follicles starting to grow/day (Pedersen, 1972). Once follicular growth is initiated, it is continuous with antral follicles observed within rat ovaries by 21 days of age (Meij-Roelofs et al., 1974; Peluso et al., 1976). Although the granulosa cells of these follicles possess FSH receptors and a limited number of LH receptors, they do not develop into preovulatory follicles but become atretic (Peluso et al., 1976).

While it is unclear why the follicles within the 21-day-old rat ovary do not mature, it does not appear to be due to their inability to respond to gonadotrophins, since large doses of gonadotrophin (PMSG) can act on the ovary of immature rats of $\geq 21$ days of age to induce follicle development and ovulation (McCormack \& Myer, 1962). However, serum gonadotrophin concentrations are relatively low in immature rats. During the juvenile state ( 21 days of age or older; uteri 
not distended with fluid), FSH is secreted at a rather constant level of $200 \mathrm{ng} \mathrm{RP}-1 / \mathrm{ml}$ while $\mathrm{LH}$ is secreted as a pulse every $30 \mathrm{~min}$ with an amplitude of $40 \mathrm{ng} \mathrm{RP}-1 / \mathrm{ml}$ (Urbanski \& Ojeda, 1985a). As the rat enters the peripubertal stage which is characterized by the presence of a uterus distended with fluid, mean LH concentrations increase. This increase in serum LH is due to an increase in the amplitude of the LH pulses from 40 to $80 \mathrm{ng} \mathrm{RP-1/ml} \mathrm{(Urbanski} \mathrm{\&} \mathrm{Ojeda,} \mathrm{1985a).} \mathrm{It} \mathrm{has} \mathrm{been}$ suggested that, in the presence of tonic FSH, an increase in the $\mathrm{LH}$ pulse amplitude stimulates both follicular growth and oestradiol- $17 \beta$ secretion within the juvenile ovary, thereby promoting the transition to the peripubertal stage of development. The present experiments were designed to test the effect of the peripubertal pattern of LH and FSH on follicular growth and oestradiol secretion of the juvenile rat ovary.

\section{Materials and Methods}

Preparation of culture medium. For Exp. I ovine luteinizing hormone (NIAMDD-oLH-25) and ovine folliclestimulating hormone (NIAMDD-oFSH-17) were used. LH contamination of the ovine FSH preparation was $0.04 \times$ ovine LH-S-1. In a dose equivalent to $200 \mathrm{ng}$ FSH-RP-1 there are $27 \mathrm{ng} \mathrm{LH}-\mathrm{RP}-1$ activity. LH and FSH concentrations in the final solutions are expressed in RP-1 units. The amount of $\mathrm{LH}$ within the medium refers to the amount of LH activity due to the ovine LH preparation and does not include the $27 \mathrm{ng}$ LH-RP-1 units of activity of the ovine FSH preparation. In Exp. II, recombinant bovine LH and FSH were used. These hormones were produced in a mammalian cell line (C-127) which is a transformed mouse fibroblast line derived from a mammary tumour (Chappel et al., 1986). These preparations are $90-95 \%$ pure and do not show biological cross-reactivity with each other.

Gonadotrophins were added to Medium 199 which was supplemented with $2 \cdot 2 \mathrm{~g} \mathrm{NaHCO} / 1,2 \mathrm{~g} \mathrm{BSA} / 1,50 \mathrm{mg}$ streptomycin sulphate/1, $62.9 \mathrm{mg} \mathrm{K}$-penicillin-G/1, $2.38 \mathrm{~g}$ Hepes/l and insulin (200 i.u./1; Lente Iletin I: Eli Lilly, Indianapolis, IN, U.S.A.). The $\mathrm{pH}$ of the medium was adjusted to $7 \cdot 4$.

The culture system. The perifusion culture system was as shown in Fig. 1. In this system the holding flasks are changed automatically by programming the microprocessor controller to open and close the solenoid valves at specific times. The mathematics which describe the hormonal fluctuations within the culture chambers have been previously published (Peluso et al., 1984a).

Animals. Immature female Wistar rats were obtained from Charles River Laboratory (Wilmington, MA, U.S.A.) and housed under controlled conditions of temperature, humidity, and photoperiod ( $12 \mathrm{~h}$ light/12 h dark; lights on at 07:00 h). The rats were used when they were 30-34 days of age in Exp. I and 34 days of age in Exp. II. On the day of the experiment, the animals were decapitated between 09:30 and 10:00 h. Only animals without fluid in their uteri were used, ensuring that the animals were in the juvenile stage. Both ovaries were removed, trimmed of fat and placed in oxygenated medium supplemented with $200 \mathrm{i}$.u. insulin $/ 1$ and $400 \mathrm{i}$.u. heparin $/ 1$. After $10-15$ min, the ovaries were weighed and then either two ovaries each from different animals (Exp. I) or individual ovaries (Exp. II) were placed in a culture chamber. The chambers were placed in a water bath. The medium flow rate through each of the chambers was $6 \mathrm{ml} / \mathrm{h}$. The medium was continuously gassed with $5 \% \mathrm{CO}_{2}$ in oxygen throughout the culture. Perifusate was collected at various times depending of the experiment. The perifusate was frozen, stored at $-20^{\circ} \mathrm{C}$ and subsequently assayed for oestradiol-17ß.

Experimental design. In Exp. I juvenile ovaries were perifused for $3 \mathrm{~h}$ with (a) control medium containing (b) $200 \mathrm{ng} \mathrm{FSH} / \mathrm{ml}$ or (c) $200 \mathrm{ng} \mathrm{FSH} / \mathrm{ml}$ and LH pulses. In this experiment LH was administered at a frequency of 2 pulses $/ \mathrm{h}$ with an amplitude of $80 \mathrm{ng} / \mathrm{ml}$ and a nadir of $25 \mathrm{ng} / \mathrm{ml}$. On each day that an experiment was conducted, ovaries were randomly assigned to all treatments and each experimental treatment was replicated 4-6 times. Four animals were autopsied at $0 \mathrm{~h}$ and one ovary from each animal served as an in-vivo control. After perifusion for $3 \mathrm{~h}$, the ovaries were fixed in formalin and prepared for histological analysis. After the first 10 min, the perifusate was collected every $30 \mathrm{~min}$ and assayed for oestradiol-17 $\beta$.

For Exp. II, juvenile ovaries were perifused for $3 \mathrm{~h}$ with (a) control medium alone or containing, (b) recombinant bovine FSH $(200 \mathrm{ng} / \mathrm{ml})$ or (c) recombinant bovine FSH and recombinant bovine $\mathrm{LH}(25 \mathrm{ng} / \mathrm{ml})$. The amount of recombinant gonadotrophin is expressed as ng of pure hormone and has not been converted to RP-1 units. In this experiment, only 3 chambers were set up on each day of the experiment. Each chamber was perifused with one of the above treatments with each treatment replicated 4 times. The perifusate was collected as one fraction and assayed for oestradiol-17 $\beta$. After the perifusion, the ovaries were fixed for histology.

Oestradiol-17 $\beta$ assay. The assay was a direct double-antibody radioimmunoassay (Pantex, Santa Monica, CA, U.S.A.). The antiserum to oestradiol cross-reacts $100 \%$ with oestradiol- $17 \beta$ and $<0.001 \%$ with oestrone and several other steroids. The assay sensitivity was $5 \mathrm{pg} / \mathrm{ml}$. All samples were assayed in duplicate. The intra- and interassay coefficients of variation were $1.8 \%$ and $6 \%$, respectively.

Analysis of follicular growth. The formalin-fixed ovaries were dehydrated, embedded in paraffin wax, sectioned at $10 \mu \mathrm{m}$ and stained with haematoxylin and eosin. The number of cells in each follicle was determined as previously described (Peluso et al., 1984b) with the following modifications. Every 5 th section was examined and only non-atretic 


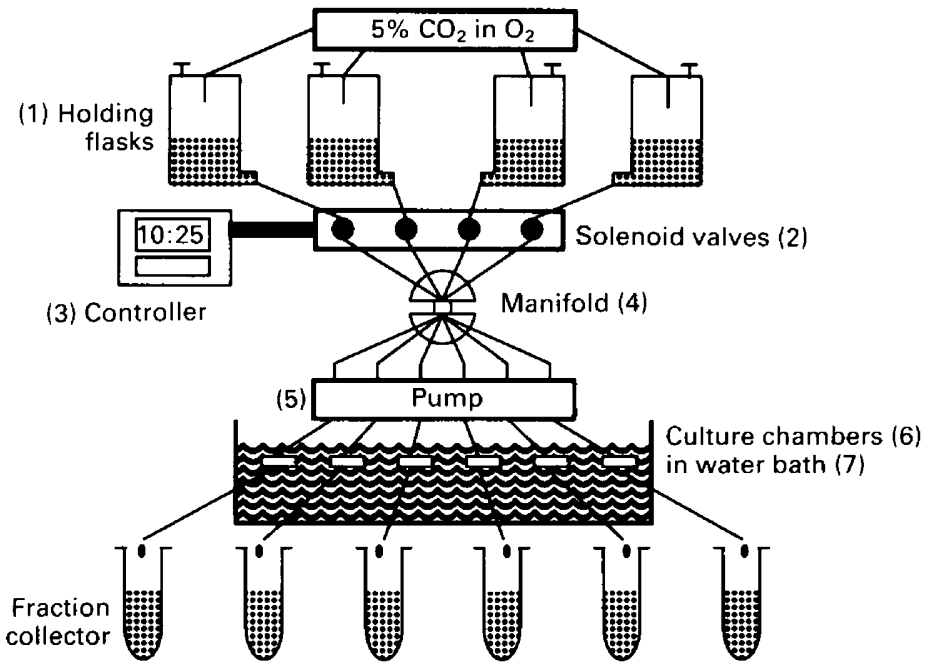

Fig. 1. A simplified diagram of the perifusion culture system. The system includes (1) a series of holding flasks with a gas inlet and a pressure release port, (2) a series of solenoid valves, (3) a microprocessor controller which controls the opening and closing of the solenoid valves, (4) low dead volume manifold which allows 4 input lines and 6 output lines, (5) a multi-channel peristaltic pump, (6) a series of 6 culture chambers and (7) a water bath set at $37^{\circ} \mathrm{C}$. The various components are connected by Teflon tubing except for the silicone tubing used in the pump segment.

follicles that contained the oocytes with a visible nucleus and/or nucleolus were counted. An image analyzer (Image Technology, Deer Park, NY, U.S.A.) was used to estimate the total number of granulosa cells for each follicle. The perimeter was estimated by tracing the basement membrane, thereby inscribing the granulosa cell layers. The perimeters of the antral cavity (if present) and the ovum were also calculated. The volume of each follicular component was mathematically determined and the volume of the antral cavity and ovum was subtracted from the volume of the entire follicle to determine the volume of the granulosa cell layers. The number of granulosa cells in the follicle was determined by dividing the volume of the granulosa cell layer by the average volume of a granulosa cell $\left(100 \mu \mathrm{m}^{3}\right)$. The relationship between diameter and number of granulosa cells within a follicle is described by the following equation: $y=0.0228 \times \times 2.5777$ where $y$ equals the number of granulosa cells per follicle and $x$ equals the average follicular diameter (Fig. 2).

Since every section of the ovary was not measured, the area of each ovarian section that was studied was measured using the image analyzer. The number of follicles in each size class was expressed per $100 \mathrm{~mm}^{2}$ of ovarian tissue.

Statistical analysis. The data generated in these experiments were analysed by analysis of variance followed by Student-Newman-Keuls multiple range test with only $P$ values $\leqslant 0.05$ considered to be significant.

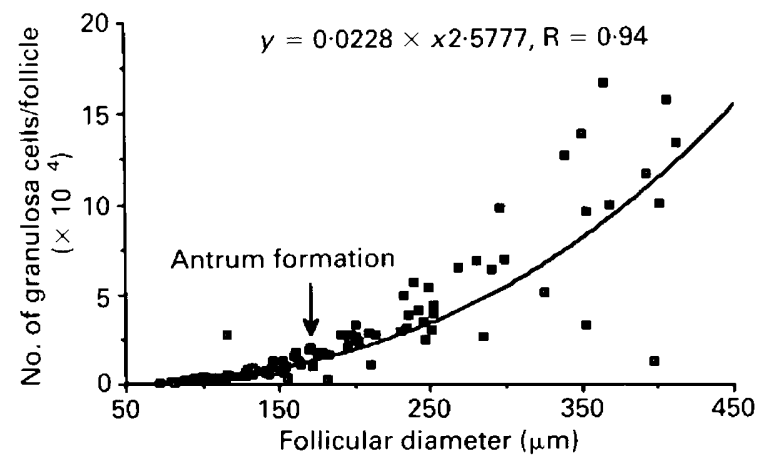

Fig. 2. The relationship between average follicular diameter and the number of granulosa cells per follicle. The line represents the best fit as described by the equation shown in this figure. 


\section{Results}

\section{Experiment $I$}

The ovaries of juvenile-stage immature rats possess follicles ranging in size from primordial (not measured in this study) to mid-size antral follicles (approximately $350 \mu \mathrm{m}$ in diameter; $\geq 80 \times 10^{3}$ granulosa cells). The greatest numbers of follicles observed were preantral follicles in the 5-9 $\times 10^{3}$ granulosa cell size class. The number of follicles in each size class decreased as the size class increased; there were an average of $4.3 \pm 1.5$ follicles in the $\geq 80 \times 10^{3}$ size class (Tables $1 \& 2$ ). After $3 \mathrm{~h}$ of perifusion with control medium, follicular distribution was not changed compared with that of the in-vivo control. In-vitro treatment with tonic FSH with or without $\mathrm{LH}$ pulses increased the number of follicles in the $\geq 80 \times 10^{3}$ size class compared to both the in-vivo and in-vitro controls $(P<0.05)$ (Table 1). Tonic FSH treatment reduced the number of follicles in the $20-39 \times 10^{3}$ cell group compared to the in-vitro control $(P<0 \cdot 05)$. In ovaries perifused with tonic FSH and pulsatile $\mathrm{LH}$, the number of follicles in this size class was maintained at control values $(P>0.05)$ (Table 1$)$.

Table 1. The effect of NIH gonadotrophin treatments on follicular distributions within immature rat ovaries after $3 \mathrm{~h}$ of perifusion

\begin{tabular}{|c|c|c|c|c|}
\hline \multirow[b]{2}{*}{$\begin{array}{l}\text { Follicle size } \\
\text { class } †\end{array}$} & \multicolumn{4}{|c|}{ Treatments } \\
\hline & $\begin{array}{l}\text { In-vivo } \\
\text { control }\end{array}$ & $\begin{array}{l}\text { In-vitro } \\
\text { control }\end{array}$ & $\begin{array}{l}\text { Tonic } \\
\text { FSH }\end{array}$ & $\begin{array}{c}\text { Tonic FSH + } \\
\text { pulsed LH }\end{array}$ \\
\hline$\geq 80$ & $4 \cdot 3 \pm 1 \cdot 5$ & $4.5 \pm 0.4$ & $11 \cdot 7 \pm 1 \cdot 1^{*}$ & $9 \cdot 2 \pm 2 \cdot 0^{*}$ \\
\hline $40-79$ & $3.9 \pm 2.3$ & $10 \cdot 5 \pm 2 \cdot 3$ & $4.3 \pm 1.8$ & $9.2 \pm 4.9$ \\
\hline $20-39$ & $7 \cdot 3 \pm 3 \cdot 8$ & $10.5 \pm 3.5$ & $1 \cdot 6 \pm 1 \cdot 5^{*}$ & $11 \cdot 9 \pm 1 \cdot 1$ \\
\hline $10-19$ & $9 \cdot 6 \pm 4.7$ & $9 \cdot 6 \pm 2 \cdot 1$ & $7 \cdot 6 \pm 3 \cdot 1$ & $10.9 \pm 3.4$ \\
\hline $5-9$ & $15 \cdot 5 \pm 2.0$ & $12 \cdot 1 \pm 4 \cdot 7$ & $9 \cdot 7 \pm 3 \cdot 1$ & $9 \cdot 5 \pm 3 \cdot 1$ \\
\hline
\end{tabular}

Values are mean number of follicles $/ 100 \mathrm{~mm}^{2}$ ovarian tissue. Four ovaries were examined in each group.

*Significantly different from in-vitro control values in the same size class $(P<0.05)$.

$\nmid$ No. of cells/follicle $\times 1000$.

Juvenile ovaries perifused with control medium secreted oestradiol-17 $\beta$ at a constant rate throughout the 3 -h perifusion with a total of $8 \cdot 9 \pm 2 \cdot 1 \mathrm{pg}$ oestradiol-17 $\beta / \mathrm{mg}$ ovarian tissue being secreted. Neither tonic FSH nor tonic FSH and pulsatile LH altered the pattern (Fig. 3) or the total amount of oestradiol-17ß secretion $(16 \cdot 3 \pm 5 \cdot 1 \mathrm{pg} / \mathrm{mg}$ for $\mathrm{FSH} ; 10 \cdot 2 \pm 1 \cdot 3 \mathrm{pg} / \mathrm{mg}$ for FSH $+\mathrm{LH}$ pulses).

\section{Experiment II}

Although exposure to recombinant FSH tended to increase the number of follicles in the $\geq 80 \times 10^{3}$ size class compared to in-vitro controls, this increase was not significant $(P>0.05)$. However, treatment with recombinant FSH plus recombinant $\mathrm{LH}$ increased the number of follicles in this class compared to that in in-vitro controls or those treated with recombinant FSH alone $(P<0.05)$ (Table 2). Recombinant gonadotrophin treatment did not affect oestradiol secretion; values (total pg of oestradiol secreted/mg ovarian weight) being $14.4 \pm 3.4$ for in-vitro controls, $10.9 \pm 1.9$ for recombinant FSH and $13.3 \pm 1.6$ for recombinant FSH plus recombinant LH.

\section{Discussion}

The present results demonstrate that FSH and LH induce follicular growth within juvenile stage ovaries. Although very small quantities of $\mathrm{LH}$ are needed (i.e. contamination levels found in the 
Table 2. The effect of recombinant gonadotrophin treatments on follicular distributions within immature rat ovaries after $3 \mathrm{~h}$ of perifusion

\begin{tabular}{|c|c|c|c|}
\hline \multirow[b]{2}{*}{$\begin{array}{l}\text { Follicle size } \\
\text { class } \dagger\end{array}$} & \multicolumn{3}{|c|}{ Treatments } \\
\hline & $\begin{array}{l}\text { In-vitro } \\
\text { control }\end{array}$ & $\begin{array}{l}\text { Tonic } \\
\text { FSH }\end{array}$ & $\begin{array}{c}\text { Tonic FSH + } \\
\text { tonic } \mathbf{L H}\end{array}$ \\
\hline $\begin{array}{l}\geq 80 \\
40-79\end{array}$ & $\begin{array}{l}3.9 \pm 1.6 \\
1.3 \pm 0.7\end{array}$ & $\begin{array}{l}8.0 \pm 2 \cdot 1 \\
3.6 \pm 0.4\end{array}$ & $\begin{array}{c}15.2 \pm 0.5^{*} \\
4.9 \pm 2.9\end{array}$ \\
\hline $20-39$ & $3.9 \pm 2.2$ & $3.9 \pm 1.9$ & $9.4 \pm 1.4$ \\
\hline $10-19$ & $6.1 \pm 2.7$ & $3 \cdot 5 \pm 1 \cdot 3$ & $5.6 \pm 0.8$ \\
\hline $5-9$ & $12 \cdot 3 \pm 5 \cdot 1$ & $10 \cdot 1 \pm 2 \cdot 3$ & $8 \cdot 4 \pm 2 \cdot 1$ \\
\hline
\end{tabular}

Values are mean \pm s.e.m. number of follicles $/ 100 \mathrm{~mm}^{2}$ ovarian tissue. Four ovaries were examined in each group.

* Significantly different from other values in the same size class $(P<0.05)$.

$\dagger$ No. of cells/follicle $\times 1000$.

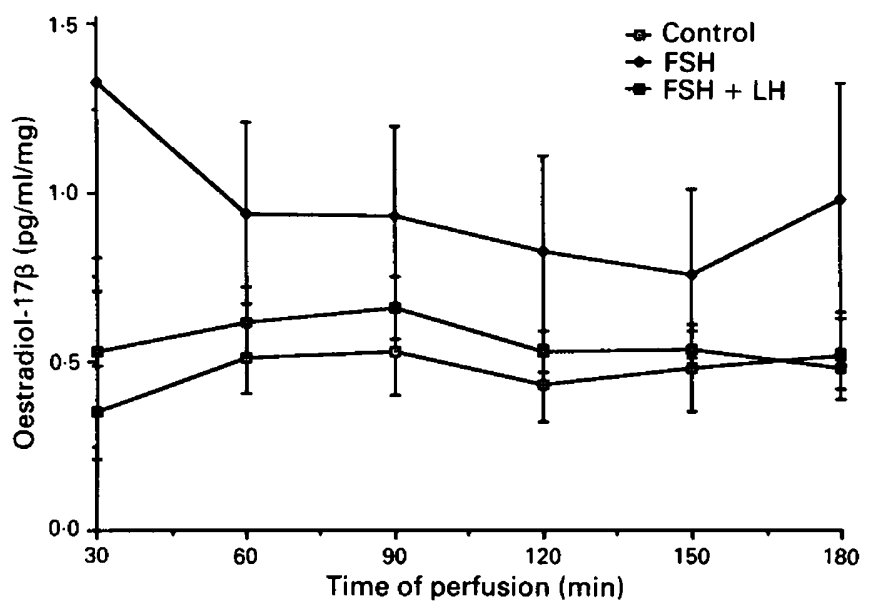

Fig. 3. The effect of LH and FSH treatment on oestradiol secretion from juvenile ovaries during $3 \mathrm{~h}$ of perifusion. Values represent a mean \pm s.e.m. of 6 observations per group.

NIH-FSH preparations), the results from Exp. II clearly demonstrate that both LH and FSH are needed to stimulate follicular growth in vitro. These observations confirm previous findings that FSH alone cannot support follicular growth in vitro (Peluso et al., 1984b) or in vivo (Lostroh \& Johnson, 1966). In addition, the present study indicates that gonadotrophins promote growth of a specific size class of follicle depending on the treatment tested.

When juvenile-stage ovaries are exposed to NIH-FSH, the number of mid-size antral follicles ( $\geq 80 \times 10^{3}$ cell-size class) increases at the expense of the number of small antral follicles (20$39 \times 10^{3}$ cell size class), indicating that tonic NIH-FSH with contaminating levels of LH stimulate small antral follicles to grow into larger follicles. Simultaneous treatment with tonic NIH-FSH and LH pulses increases the number of mid-size antral follicles without decreasing the numbers of small antral follicles. Roy \& Greenwald (1986) have shown that LH can increase $\left[{ }^{3} \mathrm{H}\right]$ thymidine incorporation into DNA of isolated preantral follicles in vitro. This observation supports the concept that 
exposure to higher LH amounts, administered in a pulsatile pattern in Exp. I, acts to promote preantral follicles to grow. FSH plus LH also increased the number of mid-size antral follicles without depleting the population of small antral follicles. This may be accounted for by the fact that the $25 \mathrm{ng} / \mathrm{ml}$ dose of LH used in Exp. II has enhanced biological activity due to its purity (Chappel et al., 1986) and may possess LH activity more similar to that of the pulsatile LH treatment than to the NIH-FSH preparation. Therefore, these in-vitro studies demonstrate that low tonic levels of FSH and $\mathrm{LH}$ combined with the pulsatile pattern of $\mathrm{LH}$ act on the juvenile ovary to stimulate preantral and small antral follicles to grow. Since this gonadotrophin treatment mimics that of rats in the peripubertal stage of development (Urbanski \& Ojeda, 1985a), it is proposed that this pattern of stimulation acts in vivo to provide a population of mid-size antral follicles that can be stimulated to develop into preovulatory follicles in response to an appropriate hormonal signal. The nature of the stimulus needed to induce these mid-size antral follicles to continue to develop into preovulatory follicles remains to be determined.

After perifusion of the ovary, follicles may enlarge due to accumulation of fluid within the antrum and this might be misinterpreted as actual growth. For this reason, the volume of the granulosa cell layer of each follicle was determined and used to estimate the number of granulosa cells. This technique, while considerably more time consuming, ensured that, in these studies, the observed changes in follicular populations were the result of an increase in the number of granulosa cells and not the accumulation of fluids within the antrum. This study further demonstrates how rapidly granulosa cells can proliferate in response to the appropriate stimuli. A comparison with in-vivo data indicates that this rapid proliferation of granulosa cells observed in vitro also occurs in vivo (Peluso, 1988).

The immature rat ovary is capable of secreting small amounts of oestradiol by 7 days of age with the amount of oestradiol secreted increasing with age (Ojeda et al., 1986). Isolated hamster follicles at the small antral stage are able to synthesize and secrete oestradiol (Roy \& Greenwald, 1987). The juvenile rat ovary contains many small antral follicles and these follicles are presumably responsible for the basal oestradiol secretion rate observed in this study. The gonadotrophin treatments used in these studies failed to increase oestradiol secretion. This confirms previous findings that in perifusion culture a rapid gonadotrophin-induced increase in oestradiol secretion is not consistently observed unless ovaries are taken from peripubertal animals (Urbanski \& Ojeda, 1985b; Peluso \& Steger, 1987). The mechanism within the juvenile ovaries which allows gonadotrophins to induce follicular development without promoting oestradiol secretion is unknown. Tonic LH treatment has also been shown to stimulate the development of follicles within the adult metoestrous rat ovary without increasing oestradiol secretion (Peluso et al., 1984b). These observations suggest that the separation of the growth-promoting and steroidogenic properties of gonadotrophin stimuli is not due to some unique characteristic of the juvenile ovary, but rather may be related to the amounts and/or pattern of $\mathrm{LH}$ and $\mathrm{FSH}$ stimulation.

I thank NIAMADD for the gifts of FSH and LH; Dr Scott Chappel for the gift of the recombinant gonadotrophins; and Ms Sally Kulis and Monica Cazzetta for excellent technical assistance. This work was supported in part by a grant from the University of Connecticut Research Foundation.

\section{References}

Chappel, S., Zabrecky, J., Hyman, L., Nugent, N., Gordon, K. \& Berstine, E. (1986) Characterization of bovine luteinizing hormone (bLH) produced by recombinant DNA technology. Endocrinology 118, Suppl., 183, Abstr. 610.

Lostroh, A.J. \& Johnson, R.E. (1986) Amounts of interstitial cell-stimulating hormone and folliclestimulating hormone required for follicular de- velopment, uterine growth and ovulation in the hypophysectomized rat. Endocrinology 79, 991-996.

McCormack, C.E. \& Meyer, R.K. (1962) Ovulating hormone release in gonadotropin treated immature rats. Proc. Soc. exp. Biol. Med. 110, 343-346.

Meijs-Roelofs, H., Ullenbroek, J., Osman, P. \& Welschen, R. (1974) Serum levels of gonadotropins and follicular growth in prepubertal rats. In The Development and 
Maturation of the Ovary and its Function, pp. 3-11. Ed. H. Peters. Excerpta Medica, Amsterdam.

Ojeda, S.R., Urbanski, H.F. \& Ahmed, C.E. (1986) The onset of female puberty: studies in the rat. Recent Prog. Horm. Res. 42, 385-441.

Pedersen, T. (1972) Follicle growth in the mouse ovary. In Oogenesis, pp. 361-376. Eds J. D. Biggers \& A. W. Schuetz. University Park Press, Baltimore.

Peluso, J.J. (1988) Follicular development and function in vitro. In The Development and Function of the Reproductive Organs. Eds A. Tsafriri \& A. Eshkol. Raven Press, New York (in press).

Peluso, J.J. \& Steger, R.W. (1987) Role of LH pulse amplitude and the rate of LH increase on oestradiol$17 \beta$ secretion by immature rat ovaries in perifusion culture. J. Reprod. Fert. 80, 629-633.

Peluso, J.J., Steger, R.W. \& Hafez E. (1976) Development of gonadotrophin-binding sites in the immature rat ovary. J. Reprod. Fert. 47, 55-58.

Peluso, J.J., Gruenberg, M.L. \& Steger, R.W. (1984a) Regulation of ovarian follicular growth and steroidogenesis by low-amplitude LH pulses. Am. J. Physiol. 246, R184-189.
Peluso, J.J., Luttmer, S. \& Gruenberg, M.L. (1984b) Modulatory action of FSH on LH-induced follicular growth in rats. J. Reprod. Fert. 72, 173-177.

Roy, S.K. \& Greenwald, G.S. (1986) Effects of FSH and LH on incorporation of $\left[{ }^{3} \mathrm{H}\right]$ thymidine into follicular DNA. J. Reprod. Fert. 78, 201-209.

Roy, S.K. \& Greenwald, G.S. (1987) In vitro steroidogenesis by primary to antral follicles in the hamster during the periovulatory period: effects of folliclestimulating hormone, luteinizing hormone and prolactin. Biol. Reprod. 37, 39-46.

Urbanski, H.F. \& Ojeda, S.R. (1985a) The juvenileperipubertal transition period in the female rat: establishment of a diurnal pattern of pulsatile luteinizing hormone secretion. Endocrinology 117, 644-649.

Urbanski, H.F. \& Ojeda, S.R. (1985b) In vitro simulation of prepubertal changes in pulsatile luteinizing hormone release enhances progesterone and $17 \beta$ estradiol secretion from immature rat ovaries. Endocrinology 117, 638-643.

Received 20 January 1988 